\title{
MENJAJAKI KEBERADAAN Saccharum Spp DI PAPUA MELALUI PENDEKATAN ARKEOLOGI \\ (Exploring the Existence of Saccharum spp in Papua through archaeological approach)
}

\author{
Marlin Tolla \\ Balai Arkeologi Papua, Jalan Isele, Kampung Waena, Distrik Heram, Kota Jayapura 99358 \\ Telepon (0967) 572467, Faksimile (0967) 572467 e-mail: marlin_felle@yahoo.de
}

INFO ARTIKEL

Histori artikel

Diterima: 28 Juli 2016

Direvisi: 8 Agustus 2016

Disetujui: 14 Oktober 2016

\section{Keywords:}

Sugarcane,

Saccharum spp Erianthu arundinaceus,

Papua

\section{Kata kunci:}

tebu,

Saccharum spp Erianthus arundinaceus,

Papua

\begin{abstract}
This paper aims to propose a discussion about the existence of Saccharum spp in Papua which is based on archaeological and ethnographic study. The academic discipline such as literary studies, archaeology, ecology etc been so intensely involved in answering the question about the origins of Saccharum spp. Unpublished research together with some previously published results also etnography data is provide in this paper to explore the possibility and an explanation of cultural process especially the the influence of the Holocene period in the introduction for the growth of plants, such as Saccharum spp. It is concluded that Papua has long played a kөy role in the development of plants including Saccharum spp.
\end{abstract}

\begin{abstract}
ABSTRAK
Tulisan ini bertujuan untuk mendiskusikan mengenai keberadaan jenis Saccharum.spp di Papua yang didasarkan pada data arkeologi dan juga data etnografi. Penelitian mengenai Saccharum spp telah lama menjadi bahan penelitian oleh beberapa disiplin ilmu seperti: arkeologi, lingkungan, bahasa dan lain sebagainya telah sangat aktif dalam menjawab berbagai macam pertanyaan terutama terkait dengan asal usul dari tanaman Saccharum spp. Adapun data yang diulas dalam tulisan ini yakni berasal dari beberapa tulisan baik itu yang pernah dipublikasikan, tulisan yang tidak dipublikasikan dan juga tidak tertinggal data etnografi. Data-data ini dimaksudkan untuk memberikan penjelasan serta kemungkinan atas proses budaya dari tumbuhan termasuk Saccharum spp baik yang ditemukan dalam situs-situs arkeologi maupun yang digunakan dalam suku-suku yang ada di Papua sekarang ini. Kesimpulan yang ditarik dalam tulisan ini adalah adanya kemungkinan yang menjelaskan tentang peranan Papua pada masa lalu sebagai tempat asal tumbuh kembangnya beberapa jenis tumbuhan termasuk Saccharum spp.
\end{abstract}

\section{PENDAHULUAN}

Salah satu pokok penting dalam menyingkapkan permasalahan yang berkaitan dengan kolonisasi pada masa prasejarah di Papua yaitu menyangkut penentuan asal usul beberapa jenis tanaman yang ditemukan pada situssitus prasejarah di Papua seperti tebu. Seperti halnya di beberapa daratanAsia Tenggara termasuk Papua, imigran seperti penutur Austronesia telah membawa pengaruh besar terhadap perkembangan beberapa unsur budaya seperti bahasa, pembuatan gerabah, kemampuan berlayar dan juga keahlian dalam bercocok tanam. Berkaitan dengan pertanian penutur Austronesia diperkirakan menjadi pelopor berkembang luasnya budidaya bercocok tanam hingga sekarang ini. Namun kemudian yang menjadi pertanyaan adalah apakah semua tumbuhan yang dibudidayakan oleh suku-suku di Papua pada masa ini merupakan hasil domestikasi dari penutur Austronesia? Ataukah malah sebaliknya tumbuhan seperti tebu merupakan tumbuhan yang justru berasal dari Papua dan daerah sekitarnya seperti Wallacea dan juga 
Pasifik?

Tebu dalam bahasa latin disebut Saccharum spp, berarti gula. Kata Saccharum berasal dari bahasa Sanskrit yaitu Sarkara (Heinz, 1987: 54). Tanaman tebu yang saat ini dibudidayakan di beberapa tempat salah satunya di Papua adalah tanaman hibrida yang berasal dari famili Saccharum officinarum dan Saccharum Spontaneum dan Erianthus arundinaceus (Dillon et. al., 2007). Tanaman yang menyerupai tongkat atau batang yang memiliki daun pada setiap jengkalnya dengan beberapa meter panjangnya mengandung kadar air yang sangat besar dan juga konsentrasi sukrosa yang tinggi. Adapun perbedaan antara Saccharum officinarum dan spontaneum adalah terletak pada bagian akar. Saccharum officinarum pada umumnya mengandung akar yang lebih sedikit dibandingkan Saccharum spontaneum (Moore, 1987) yang merupakan faktor yang menentukan ketahanan terhadap tekanan lingkungan sekitar. Sedangkan jenis Erianthus arundinaceus merupakan salah satu jenis tebu liar yang diameternya lebih kecil dibandingkan $S$. officinarum yang tumbuh pada daerah yang berair dan juga memiliki curah hujan yang tinggi.

Saccharum spp sangat banyak ditemukan di Papua baik itu di dataran tinggi maupun di dataran rendah yang sekaligus dijadikan sebagai salah satu bahan makanan yang paling digemari oleh suku-suku di Papua dan juga digunakan sebagai peralatan hidup. Tidak saja itu, bahkan di daratan Asia seperti India, Thailand, Cina dan lain sebagainya, tebu menjadi salah satu komoditi handal dari sekian tanaman pangan dalam kegiatan ekspor dan impor ke negara-negara maju saat ini. Melihat sisi pentingnya tebu dalam kehidupan manusia saat ini maka munculah beberapa perdebatan diantara para ahli yakni terutama berkaitan dengan asal usul dari tebu tersebut. Keberadaan berbagai jenis Saccharu spp di Papua memunculkan pertanyaan apakah dikehadirannya diperkenalkan oleh imigran yang datang di Papua, faktor alam ataukah tumbuhan yang sifatnya endemik?

Metode yang dilakukan dalam penelitian ini yaitu antara lain pengumpulan data dengan menggunakan studi pustaka dengan mengkaji beberapa referensi baik itu bersumber dari buku mapun artikel yang berkaitan dengan topik penelitian yaitu tebu. Selain itu data etnografi digunakanuntukmenguji permasalahan yang dihadapi contohnya dalam hal menelusuri penggunaan tebu dalam suku-suku yang berdiam di beberapa daerah di Papua baik yang dikomsumsi setiap hari maupun yang digunakan sebagai alat dalam mendukung kegiatan keseharian mereka.

\section{PEMBAHASAN}

Rekonstruksi penyebaran tebu serta asal-usulnya telah menjadi salah satu topik yang hangat dibicarakan oleh para ahli pada masa lalu bahkan masih berkembang hingga pada masa sekarang. Perdebatan yang berkembang terutama tentang bagaimana proses budidaya tebu yang berkembang khususnya di Papua. Jenis Saccharum officinarum kemungkinan telah menjadi salah satu jenis yang telah di budidayakan semenjak zaman prasejarah di kawasan Asia Tenggara yang diperkirakan berkembang di Papua (Sreenivasan et. al. 1987; Roach dan Daniels, 1987).

Beberapa ahli mengemukakan bahwaAsia Tenggara merupakan pusat utama berkembangnya tanaman tebu 
(Carl Sauer, 1969; Roach dan Daniels, 1987). Hal ini didasarkan pada jumlah spesies yang ditemukan paling banyak di Asia khususnya Asia Tenggara yakni berjumlah 25 native spesies dari jumlah keseluruhan yakni berkisar 3540 genus tebu di dunia (Darke, 1999; Bonnett et. al., 2008). Jika didasarkan pada bukti tersebut maka pertanyaan selanjutnya adalah jika Asia Tenggara adalah 'rumah' dari Saccharum spp, maka dimana tepatnya daerah asal mulanya berkembang.

Masih berkaitan dengan itu, tebu yang dikonsumsi yakni Saccharum officinarum beserta jenis liar Erianthus arundinaceus di Papua telah memunculkan berbagai macam dugaan antara lain, diperkirakan telah melalui proses domestikasi sebelumnya seperti yang dikemukakan oleh beberapa ahli tentang adanya keterlibatan penutur Austronesia dalam pembudidayaannya yang menyebar hingga ke daerah Pasifik dan juga Papua. Berdasarkan bukti linguistik, Blust (1976) menyatakan bahwa tebu berasal dari Cina Selatan dan dikembangkan oleh penutur Austronesia ke berbagai daerah. Namun hal itu kemudian mendapat kritikan oleh beberapa ahli karena adanya ketidakcocokan yang ditunjukkan oleh bukti-bukti arkeologi (Bellwood, 1981; Spriggs, 1982).

Selain itu dari bukti-bukti germplasma dari tumbuhan tebu seperti Erianthus arundinaceus serta $S$. officinarum, kedua jenis ini tidak tumbuh secara baik di bagian selatan Cina dan juga di Taiwan (Heinz, 1987:53). Hasil penelitian selanjutnya juga ditunjukkan oleh penelitian linguistik yang dilakukan oleh Benediktus $(1966,1967)$ yang menunjukkan bahwa tebu kemungkinan tidak berasal dari Cina melainkan berasal dari Thailand.
Hal ini didasarkan pada penelitian linguistik yang menunjukkan bahwa kata Tebu merupakan bagian dalam kelompok kata bahasa Austro-Thai. Selain itu hipotesa mengenai asal usul tebu juga berikan oleh beberapa ahli yang menduga tebu berasal dari India, namun kemudian dibantah oleh Deerr (1911) yang menyatakan bahwa jenis tebu yang terdapat di India adalah jenis tebu yang berbeda jenis yaitu Saccharum barberi. Selanjutnya berdasarkan penelitiannya Deerr mengemukakan bahwa jenis Saccharum officinarum diperkirakan berasal dari daerah di sekitar garis Wallacea dan Papua.

Dalam rangka memahami asal usul tebu dan perkembangannya di Papua maka ada beberapa pokok penting yang perlu diperhatikan dalam penelusurannya contohnya adalah praktek pertanian. Seperti yang nyatakan oleh Spriggs bahwa perkembangan pertanian di Papua adalah sebuah proses yang tidak bisa dipisahkan dari masa-masa yang sudah ada sebelumnya yakni masa sebelum penutur Austronesia memasuki Papua dan wilayah Pasifik, mengingat kurangnya bukti-bukti yang kuat terutama dari data arkeologi (Spriggs, 1996:528-529).

Semenjak teori yang mengacu pada kolonisasi penutur Austronesia di Papua dimunculkan oleh para ahli (Spriggs,1984), pengkajian terhadap proses budaya gencar dilakukan oleh berbagai disiplin ilmu tidak terkecuali mengenai pemanfaatan lingkungan, kemunculan berbagai jenis rumput dan lain sebagainya beserta pengetahuan tentang berkembang biaknya beberapa jenis tanaman seperti Saccharum spp. Adapun kedatangan komunitas Austroloid di Papua diperkirakan terjadi pada awal 50000 tahun yang lalu, 
pertanggalan pertama kali dilakukan yakni sekitar 26000 BP (White dan Allen 1980). Selain itu mengacu pada bukti linguistik, Wurm (1983) mendeteksi adanya tiga kelompok bahasa yang bermigrasi ke Papua sekitar 15000, 10000 dan 4000-5000 BP. Jika didasarkan pada hal tersebut maka kemungkinan akan pengenalan jenis Saccharum spp tidak menutup kemungkinan dilakukan sebelum pengenalan teknik bercocok tanam dikenal secara luas di Papua pada 9000 BP (Golson, 1983).

Hingga sekarang ini, bukti arkeologi dianggap belum bisa menjawab keberadaan tebu di Papua. Bukti arkeobotani dari tanaman tebu yang diduga ditemukan di Situs Yuku (Bulmer, 1975: 31), di wilayah pegunungan Papua New Guinea hampir tidak bisa dipastikan (Yen, 1998: 31). Satu-satunya informasi yang diperkirakan dapat digunakan untuk merekonstruksi asal usul tebu yakni dari bukti linguistik terutama untuk istilah tebu, 'Cebus', tetapi juga masih dianggap masih lemah karena berdasarkan tipologinya kata 'Cebus' dianggap masih mendapatkan pengaruh dari protoAustronesia di Taiwan ca 5500 tahun yang lalu (Pawley, 2007). Berbeda dengan hasil yang didapatkan dari arkeologibotani dan linguistik, Lebot (1999) memberikan hasil yang lain yakni dari hasil yang didapatkannya dari biomolekuler yang menunjukkan tentang sebagian besar dari tanaman yang berkembang di Pasifik terutama Saccharum officinarum berasal dari Papua dan daerah sekitar Melanesia yang merupakan pusat penting keanekaragaman spesies yang ada di Asia (Lebot, 1999:626).

Bukti dari Arkeologibotani dan analisis biomolekuler saling mendukung terhadap landskap serta lingkungan di setiap interior pulau Papua untuk pertumbuhan tebu. Adapun bukti dari arkeologi botani telah menunjukkan mengenai keberadaan dan penggunaan berbagai macam tanaman di dataran tinggi Papua pada awal hingga pertengahan Holosen dan sebelum adanya kontak dengan Asia Tenggara (Lilley, 2006: 172).

Keadaan lingkungan pada masa awal Holocene menjadi sebuah faktor penentu akan kehadiran beberapa tumbuhan pada masa prasejarah terutama di dataran tinggi. Terdapatnya bukti-bukti akan kehadiran dan budidaya tanaman dengan memanfaatkan lahan basah secara intensif pada awal Holocene menjadi salah satu faktor pemicu berkembangnya jenis-jenis tanaman di Papua tidak terkecuali tebu (Denham, 2004:179).

Beberapa situs yang memberikan tanda perubahan lingkungan seperti yang ditunjukkan di Situs Kuk yakni tidak ditemukannnya intervensi terhadap lingkungan pada akhir masa Pleistosen. Setelah itu menunjukkan perubahan khususnya pada pertengahan Holosen (6800-5700 kal BP) ditandai dengan pembentukan padang rumput, munculnya hutan sekunder dan lain sebagainya (Haberle, 2002; Denham, Haberle, dan Lentfer, 2004; Powell, 1970a,). Hal ini juga terjadi di Lembah Wahgi yang menunjukkan perubahan lingkungan pada pertengahan Holosen ditandai dengan tertutupnya bagian lembah dengan padang rumput pada masa itu (Powell, 1982b: 218).

Pada masa awal hingga pertengahan Holosen bukti bercocok tanam khususnya di dataran tinggi Papua relatif kuat di perkirakan. Hal ini didasarkan pada transformasi 
landskap dan ketergantungan pada agro-ekosistem (Denham, et.al. 2003). Lahan basah yang ditemukan pada masa Holosen pada Situs Kuk sangat berperan kuat dalam proses pertumbuhan tanaman dan juga memberikan bukti langsung akan adanya perubahan antropogenik pada masa itu. Walaupun begitu kesimpulan ini bukanlah hasil akhir dan masih membutuhkan data-data ilmiah lainnya pada situs-situs prasejarah lainnya di Papua. Selain itu, data etnografi juga dianggap sangat berperan penting dalam menjawab permasalahan tersebut seperti yang akan dipaparkan pada paragrap selanjutnya.

Adapun data etnografi seperti yang ditunjukkan oleh suku Korowai yang berdiam di daerah perbatasan antara Merauke dan Papua New Guinea. Suku Korowai sangat giat mengkomsumsi tebu selain makanan pokok lainnya seperti sagu, petatas dan lainnya. Di hutan sekitar rumah pohon dan terutama di sepanjang sungai, berbagai sayuran berdaun hijau, spesies rumput, dan terutama tebu tumbuh subur. Khusus untuk tanaman tebu, dalam bahasa Korowai tebu atau Saccharum officinarum; Korowai: baliam sangat populer sebagai sumber energi dikonsumsi setiap hari terutama selama perjalanan dalam kegiatan berburu di hutan. Tebu yang juga biasa disebut gelen oleh suku Korowai, dikumpulkan untuk dimakan bersamasama dengan sagu (Van enk, de vries, 1997).

Pada suku Korowai dalam setiap tahunnya tebu disajikan dalam festival ucapan syukur yang merupakan upacara yang dilakukan secara turun temurun. Ungkapan syukur ini dalam bahasa Korowai disebut Dufekho baliampeko gelempekho bufekho khawfekh. Tebu biasanya disajikan pada bulan dan hari tertentu yaitu bulan ke-3 hari ke-2 bersama dengan sagu, petatas, sayur dan lain sebagainya. Tradisi ini dilakukan khusus sebagai tanda ucapan syukur yang dilakukan terhadap hasil panen yang diperoleh selama setahun. Tebu menjadi salah satu makanan favorit yang disediakan dalam upacara ini dan disajikan kepada tamu-tamu undangan yang terdiri dari totangga dan kerabat. Sisa dari hasil panen tersebut akan disimpan dalam tempat penyimpanan (Van enk, de vries, 1997:38).

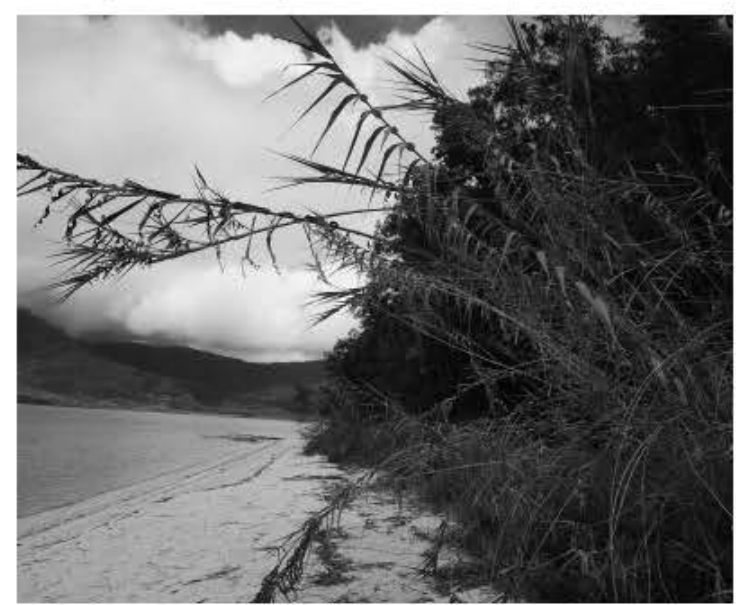

Gambar 1. Erianthus arundinacous tumbuh di pinggir Danau Anggi, Pegunungan Arfak, Papua Barat (dokumentasi Marlin)

Selain itu data etnografi juga ditunjukkan oleh suku yang berdiam di Pegunungan Arfak, tebu jenis Saccharum officinarum dan Erianthus arundinaceus tumbuh subur di sekitar rumah serta lahan pertanian. Selain itu jenis Erianthus anundinaceus dijadikan sebagai salah satu bahan baku dalam pembuatan panah (jubi) yakni dengan cara dibersihkan dan dikeringkan terlebih dahulu kemudian ditajamkan pada bagian ujungnya atau sambungkan dengan mata panah yang biasanya terbuat dari batu atau logam. Erianthus arundinaceus tumbuh subur di sekitar Danau Anggi dan dijadikan sebagai salah satu bahan pokok pembuatan panah secara turun temurun hingga sekarang ini. 
Khusus untuk jenis Erianthus arundinaceus, kromosom yang ditemukan pada jenis ini terdiri atas $\mathbf{4 1}$ kloni yang mencakup semua bidang (Sreenivasan, 1983). Morfologi dari kloni yang dimiliki oleh Erianthus arundinaceus adalah merupakan hasil ekspedisi pada masa lalu. Terhitung 1.976 ekspedisi yang dilakukan yang menghasilkan peta distribusi habitat dari Erianthus arundincaeus yang meliputi Papua dan juga daerah yang berada di garis Wallacea (Grassl, 1967).

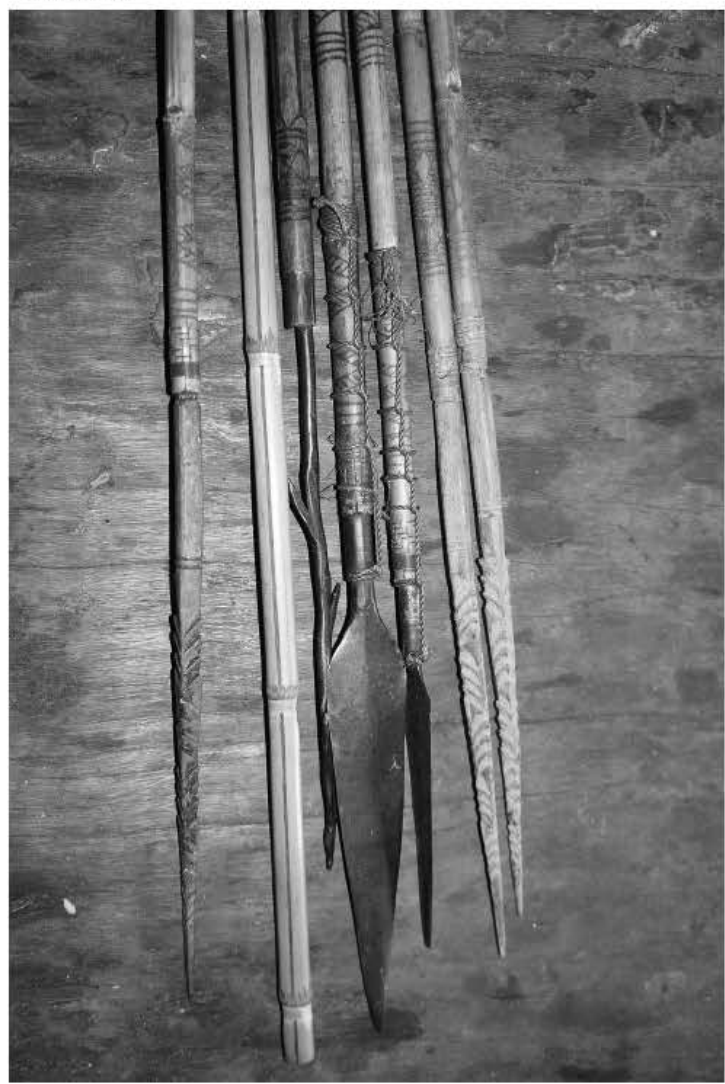

Gambar 2. Jubi atau panah yang digunakan oleh suku-suku yang berdiam di Pegunungan Arfak untuk berburu di hutan (dokumentasi Marlin)

Berkaitan dengan pemanfaatan Erianthus arundinaceus dalam sukusuku yang berdiam di sekitar Danau Anggi, Pegunungan Arfak, pemilihan bahan baku dalam pembuatan alat pada masa lalu sangat bergantung pada lingkungan sekitar. Untuk itu pemilihan Erianthus arundinaceus untuk pembuatan jubi (panah) sebagai alat untuk berburu tentu telah melalui berbagai macam pertimbangan yang diperoleh melalui pengalaman turun temurun. Sebagai alat untuk berburu, Erianthus arundinaceus dikenal sangat ringan dan juga sangat tajam. Hal ini sangat dibutuhkan dalam kegiatan berburu terutama dalam strategi untuk menangkap hewan buruan.

Walaupun data etnografi ini masih sangat dini untuk dijadikan salah satu argumen untuk menjelaskan keberadaan jenis Saccharum spp di Papua tetapi paling tidak dapat memberikan informasi mengenai peranan Saccharum spp dalam sukusuku di Papua serta dapat digunakan sebagai titik awal tentang beberapa kemungkinan dalam kaitannya dengan asal usul serta proses budaya yang menyertai keberadaan Saccharum spp di Papua. Bukti linguistik yang terdapat dalam suku Korowai menjadi hal yang menarik untuk dicermati.

Selain itu pada suku-suku di Pegunungan Arfak, Papua Barat, penggunaan salah satu jenis Saccharum spp yaitu Erianthus arundinaceus sebagai bahan baku dari pembuatan jubi menjadi sebuah dasar akan peranannya dalam kegiatan berburu. Seperti yang kita ketahui bahwa kegiatan berburu pada masa prasejarah dilakukan pada awal Holocene (c.11700-7800 cal BP) yang didapatkan melalui bukti arkeozoologikal di beberapa situs seperti Yuku, Kiowa, Aiburi, Batari, Kafiavana, Nombe dan Kamapuk (Aplin, 1982; Mountain,1991; White, 1972; Bulmer, 1982; White, 1972). 


\section{PENUTUP}

\begin{tabular}{|c|c|}
\hline \multirow{2}{*}{$\begin{array}{l}\text { Keberadaan jenis-jenis } \\
\text { tumbuhan di Papua baik yang } \\
\text { ditemukan dalam situs-situs arkeologi } \\
\text { maupun yang masih dibudidayakan } \\
\text { oleh suku-suku yang berdiam di Papua } \\
\text { sekarang ini, menjadi indikator atas } \\
\text { kemungkinanakan pengembangbiakan } \\
\text { tumbuhan pada masa lalu baik melalui } \\
\text { imigran maupun terjadi karena proses } \\
\text { alam. Saccharum spp diperkirakan } \\
\text { menjadi salah satu jenis tumbuhan } \\
\text { yang diduga berasal dari daratan Asia } \\
\text { Tenggara khususnya di sekitar Papua } \\
\text { menyebar ke arah garis Wallacea dan } \\
\text { juga Pasifik khususnya pada masa } \\
\text { awal Holocene. Hal ini ditandai oleh } \\
\text { perubahan iklim serta lingkungan yang } \\
\text { kemungkinan menjadi indikator akan }\end{array}$} & $\begin{array}{l}\text { un } \\
\text { uri }\end{array}$ \\
\hline & nya data arkeolo \\
\hline
\end{tabular}




\section{DAFTAR PUSTAKA}

Aplin, K. P., J. M. Pasveer and W. E. Boles. 1999. Late Quaternary Vertebrates from theBird's Head Peninsula, Irian Jaya, Indonesia, Including Descriptions of Two previously Unknown Marsupial Species. Records of the Western Australian Museum Supplement 57: 351-387.

Aplin, K. 1981. "Tamapuk Fauna: A Late Holocene Vertebrate Faunal Sequence from theWestern Highlands District, Papua New Guinea with Implications for Palaeoecology and Archaeology". Unpublished BA (Hons) thesis, Australian National University, Canberra.

Benedict, P. K. 1966. Austro-Thai. Behav.Sci. Notes, I:227-261.

Benedict, P. K. 1967. Austro-Thai Studies No.1 Material Culture; 2, Kinship Terms; 3, Austron-Thai and Chinese. Behav.Sci. Notes, 2: 203-232, 232-234, 275336.

Bonnett, G. D. 2008. "Identifying the Risks of Transgene Escape from Sugarcane Crops to Related Species, with Particular Reference to Saccharum Spontaneum in Australia". Trop Plant Biol. 1:58-71.

Bulmer, S. 1975. "Settlement and Economy in Prehistoric Papua New Guinea: A review of the Archaeological Evidence". J. Soc. Oceanistes, 31 (46):7-75.

Bulmer, S. 1982. "Human Ecology and Cultural Variation in Prehistoric New Guinea" in J.L. Gressitt (ed.), Biogeography and Ecology of New Guinea, pp.169206. The Hague: Junk Publishers.

Daniels, J., Smith, P., Paton, N dan Williams, C.A.1976c. "The Origin of the Genus Saccharum". Sugarcane Breed. Newsl., 36:24-39.

Daniels, J., dan C. Daniels. 1993. "Sugarcane in Prehistory". Archaeology in Oceania 28:1-7

Darke, R. 1999. The Color Encyclopedia of Ornamental Grasses: Sedges, Rushed, Restios, Cat-Tails and Selected Bamboos. Portland: Timber Press.

Denham, T. 2003. "Archaeological Evidence for /Mid-Holocene Agriculture in the Interior of Papua New Guinea: A Critical Review". Archaeology in Oceania 38 (3):159-176.

Denham, T.P ., J. Golson and P. J. Hughes. 2004. "Reading Early Agriculture at Kuk (Phase 1-3) Wahgi Valley, Papua New Guinea: the Wetland Archaeological Features". Proceedings of the Prehistoric Society, 70:259-298.

Denham, T.P., S. G. Haberle, and C. Lentfer. 2004. "New Evidence and Interpretations for Early Agriculture in Highland New Guinea". Antiquity 78:839-857.

Deerr, N. 1911. Cane Sugar: A Textbook on the Agriculture of the Sugar Cane, The Manufacture of Cane Sugar and the Analysis of Sugar-House Products Together with a Chapter on the Fermentation of Molasses. Norman Rodger, Manchester, $592 \mathrm{pp}$.

De Vries. L., Van Enk. G. J. 1997. The Korowai of Irian Jaya. Their Language in its Cultural Context. 
Dillon SL, Shapter F. M, Robert H. J., Cordeiro G, Izquierdo L, Lee SL. 2007. Domestication To Crop Improvement: Genetic Resources for Sorghum and Saccharum (Andropogoneae). Ann Bot.

D.J Heinz. 1987. Sugarcane Improvement through breeding. Volume 11. 1st edition. Elsevier.

Ellison, J. 2005. "Holocene palynology and Sea-Level Change in Two Estuaries in Southern Irian Jaya". Palaeogeography, Palaeoclimatology, Palaeoecology, 220: 291-309.

Gerrit J.Van Enk, Lourens de Vries. 1997. The Korowai of Irian Jaya. Their language in its Cultural Context.

Grivet. L. C. Daniels, J.C Glaszman , and A. D'Hont. 2004. "A Review of Recent Molecular Genetics Evidence for Sugarcane Evolution and Domestication". Ethnobotany Research and Applications 2:9-17.

Golson, J. 1983. "Man in the Central Highlands. In: Hope, G. S. Golson, J. and Allen, J. Palaeoecology and Prehistory in New Guinea". J. Hum. Evol., 12 (I):3760, pp.42-50.

Grassl, 1967. "Introgression Between Saccharum and Miscanthis in New Guinea and the Pacific Area". Proc. Int.Soc. Sugar Cane Technology, 12:995-1003.

Haberle, S. G. 1993. "Late Quaternary Environmental History of the Tari B a sin, Papua New Guinea". PhD thesis, Australian National University, Canberra.

Lilley, lan. 2006. Archaeology of Oceania: Australia and the Pacific /slands. Blackwell Publishing. Australia.

Moore, P. H. 1987. "Physiology and Control of Flowering" in: Copersucar International Sugarcane Breeding Workship. Sao Paulo: Copersucar pp 103-128.

Mountain, M-J. 1991. "Highland New Guinea Hunter-Gatherers: The Evidence of Nombe Rockshelter, Simbu, with Emphasis on the Pleistocene". 2 vols. Unpublished PhD thesis, Australian National University, Canberra.

Powell, J. M. 1970. "The Impact of Man on the Vegetation of the Mount Hagen Region, New Guinea". PhD thesis, Australian National University, Canberra.

Sreenivasan TV, Ahloowalia BS, Heinz DJ. Cytogenetics. In:Heinz Dj, editor. Sugarcane Improvement through Breeding. Amsterdam: Elseview; 1987.

Spriggs, M. 1982. "Taro Cropping Systems in the Southeast Asian-Pacifc Region: Archaeological Evidence". Archaeol. Oceania, 17 (I):7-15.

Spriggs, M. 1984. "The Lapita Cultural Complex: Origins, Distribution, Contemporaries and Successors". J.Pac.Hist., 19(4):202-223.

White, J. P. 1972. "OI Tumbuna: Archaeological Excavations in the Eastern Central Highlands, Papua New Guinea". Terra Australis 2. Canberra: Department of Prehistory, Research School of Pacific Studies, Australian National University. 